\title{
Cardia and cardiac tumor: endoscopic ultrasound video
}

A 62-year-old man presented with a 2-month history of progressive dysphagia and weight loss. Esophagogastroduodenoscopy revealed a tumor in the cardia, and a biopsy showed adenocarcinoma. He had a history of recurrent embolic cerebrovascular accidents 3 years ago and underwent warfarin therapy after these events. He was referred for locoregional staging of cardia tumor by endoscopic ultrasound (EUS).

The cardia tumor stage was T3N1. During EUS, we found a hyperechoic moving mass lesion attached to the left atrium wall. The patient underwent transthoracic echocardiography and surgery. The cardiac tumor was myxoma of the left atrium.

Endoscopy_UCTN_Code_CCL_1AB_2AC_3AB

\section{Competing interests}

None

The authors

\section{Rasoul Sotoudehmanesh ${ }^{1}$, Mohamad} Eloubeidi ${ }^{2}$

1 Digestive Disease Research Center, Digestive Disease Research Institute, Tehran University of Medical Sciences, Tehran, Iran

2 Gastroenterology, Regional Medical Center, Anniston, Alabama, United States

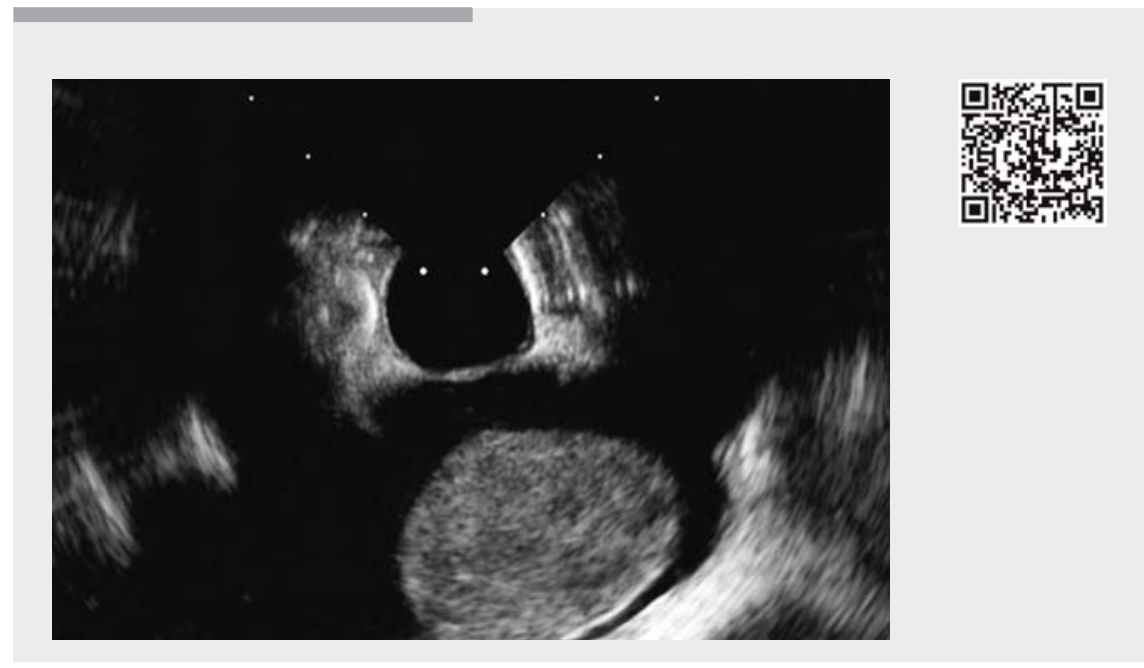

Video 1 Myxoma as a hyperechoic lesion in the left atrium.

\section{Corresponding author}

\section{Rasoul Sotoudehmanesh, MD}

Liver and Pancreaticobiliary Research Center, Digestive Disease Research Institute, Tehran University of Medical Sciences, 1411713135, Shariati Hospital, N. Kargar St., Tehran, Iran

Fax: +98-21-82415400

r.sotoudehmanesh@gmail.com

\section{Bibliography}

DOI https://doi.org/10.1055/a-0896-2657

Published online: 9.5.2019

Endoscopy 2019; 51: E269

(C) Georg Thieme Verlag KG

Stuttgart · New York

ISSN 0013-726X

\section{ENDOSCOPY E-VIDEOS}

https://eref.thieme.de/e-videos

回盾 Endoscopy E-Videos is a free access online section, reporting 回: on interesting cases and new techniques in gastroenterological endoscopy. All papers include a high quality video and all contributions are freely accessible online.

This section has its own submission website at https://mc.manuscriptcentral.com/e-videos 